\title{
Complications in Spinal Injuries (Summary of Paper) ${ }^{\star}$
}

\author{
T. Jansen, MD, R. Gjone, MD, N. Hjeltnes, MD \\ Sunnaas Rehabilitation Hospital, 1450 Nesoddtangen, Norway
}

About 60 new cases with traumatic spinal injury are registered in Norway per year and approximately $50_{\%}^{\circ}$ are admitted for treatment in the spinal unit at Sunnaas Hospital. It is a Scandinavian tradition that spinal injured patients are primarily treated in surgical departments and later on are transferred to rehabilitation hospitals. The interval between injury and admission to a spinal rehabilitation unit varies considerably. It is our experience that late admission to a specialized spinal rehabilitation unit leads to an increase in the occurrence of complications. By reviewing the medical records of 319 patients for a 10 year period with traumatic spinal injuries, the patients were divided into three groups (I), admitted within 30 days, (II) admitted between 30 and 60 days and (III) admitted more than 60 days after the date of injury (Tables I and II).

The following conclusions were made:

Nearly half the 319 patients were admitted to Sunnaas Hospital more than 60 days after injury. Important factors for the delayed transfer of the patients were limited capacity at the Sunnaas Hospital's spinal unit, operations on the spinal column as well as associated injuries. The consequences of delayed transfer appear to be an increase in the number of complications.

The frequency of urinary tract infections increased with an increased time from injury to the subsequent admission to Sunnaas Hospital. Prolonged use of a permanent catheter led to increased frequency of UTI and to a high risk of bladder stones. The frequency of severe spasticity, P.A.O. and serious contractures as well as pressure sores was clearly increased in group $3 \mathrm{com}$ pared with group 1 and 2, so also was the stay in hospital especially for the tetraplegics.

Table I

\begin{tabular}{lc}
\hline $\begin{array}{c}\text { Time from injury } \\
\text { to admission to } \\
\text { Sunnaas Hospital }\end{array}$ & $\begin{array}{c}\text { No. of patients } \\
\text { admitted }\end{array}$ \\
\hline Group 1: $<30$ days & 84 \\
Group 2: $30-60$ days & 78 \\
Group 3: $>60$ days & 157 \\
Total & $\overline{319}$ \\
\hline
\end{tabular}

Table II Categories of spinal injured patients

\begin{tabular}{cccc}
\hline & Tetraplegics & Paraplegics & Total \\
\hline Group 1 & 36 & 48 & 84 \\
Group 2 & 22 & 56 & 78 \\
Group 3 & 88 & 69 & 157 \\
\hline
\end{tabular}

* Read at the Annual Scientific Meeting of the International Medical Society of Paraplegia, Oslo, Norway, June 1986. 